\title{
Hyperpolarization-activated $\left(I_{h}\right)$ currents in auditory brainstem neurons of normal and congenitally deaf mice
}

\author{
Richardson N. Leao, Katarina Svahn, Amy Berntson and Bruce Walmsley \\ Synapse and Hearing Laboratory, The John Curtin School of Medical Research, The Australian National University, PO Box 334, \\ Canberra, ACT 0200, Australia
}

Keywords: auditory, brainstem, hyperpolarization-activated current

\begin{abstract}
We have investigated the membrane properties of brainstem auditory neurons in a mouse model of congenital deafness $(d n / d n)$. Whole-cell recordings were made from visualized neurons in slices of the medial nucleus of the trapezoid body (MNTB) and anteroventral cochlear nucleus (AVCN). We have recently demonstrated that MNTB neurons in deaf mice are more excitable than in normal mice, due in part to a reduced expression of low-threshold potassium currents. In this study, we have examined the contribution of hyperpolarization-activated $\left(I_{h}\right)$ channels to the membrane properties of MNTB and AVCN neurons. Our results show that $I_{\mathrm{h}}$ is larger in MNTB neurons from deaf mice than in normal mice. In contrast, no significant differences were found in $l_{\mathrm{h}}$ or excitability between AVCN bushy cells from $d n / d n$ and normal mice. Experimental evidence and neuronal modelling suggests that, in the MNTB of normal mice, a small contribution of $l_{\mathrm{h}}$ helps to reduce temporal summation of synaptic potentials. A larger $l_{\mathrm{h}}$ in neurons from deaf mice has a much greater effect in reducing temporal summation of synaptic potentials, counteracting to some extent the greater excitability of these cells. Our results provide further insight into the role of activity during development in regulating the membrane and firing properties of central neurons.
\end{abstract}

\section{Introduction}

Postsynaptic neuronal membrane properties play a crucial role in determining the response of a neuron to synaptic inputs. Different types of neurons express particular complements of voltage-dependent and voltage-independent (leakage) channels, appropriate to their specific physiological roles. It seems likely that the expression of these channels is regulated by neuronal activity, particularly during development when neuronal circuits are being shaped.

In the present study, we have examined the potential role of neuronal activity during development in regulating membrane properties by studying auditory brainstem neurons in congenitally deaf $(d n / d n)$ mice (Bock et al., 1982; Keats \& Berlin, 1999). Homozygous mice for the $d n$ gene (Tmc 1 gene; chromosome 19) suffer from profound asymptomatic deafness (Kurima et al., 2002). These animals display early degeneration of the organ of Corti and lack spontaneous and acoustically evoked auditory nerve activity. We have recently recorded from the auditory nerve and the anteroventral cochlear nucleus (AVCN) in age-matched normal and $d n / d n$ mice, confirming the absence of spontaneous activity from the auditory nerve in mice as young as P5 (A. Paolini, M. Youssoufian and A. Berntson, unpublished observations). In the present study, we have investigated principal cells in the medial nucleus of the trapezoid body (MNTB) and bushy cells from the AVCN (Friauf \& Lohmann, 1999) in normal and $d n / d n$ mice. MNTB cells receive large, powerful synaptic contacts, the calyces of Held, and exhibit very distinctive firing properties appropriate to their role in processing precise timing information required for sound localization. Previous studies have shown that MNTB neurons exhibit a dendrotoxin (DTX)-sensitive

Correspondence: Professor Bruce Walmsley, as above.

E-mail: Bruce.Walmsley@anu.edu.au

Received 26 October 2004, revised 25 March 2005, accepted 21 April 2005 low-threshold voltage-dependent $\mathrm{K}^{+}$current $\left(I_{\mathrm{LT}}\right)$, which prevents multiple action potentials in response to current injection or synaptic input (Brew \& Forsythe, 1995; Dodson et al., 2002). In a more recent study (Leao et al., 2004), we have shown that MNTB neurons in deaf $(d n / d n)$ mice exhibit significantly different firing properties and produce multiple action potentials in response to current injection or synaptic input, due in part to a reduced $I_{\mathrm{LT}}$. However, MNTB neurons in normal mice also exhibit a hyperpolarization-activated current $\left(I_{\mathrm{h}}\right)$ and have a very low input resistance. $I_{\mathrm{h}}$ may also play a significant role in determining the firing properties of MNTB neurons (Banks et al., 1993), and undergo developmental activity-dependent regulation. Shaikh \& Finlayson (2003) have shown in vivo that $I_{\mathrm{h}}$ plays a significant role in determining the excitability of neurons in the superior olivary complex of rats.

Recently, Oleskevich et al. (2004) have demonstrated that deafness affects the endbulb of Held-bushy cell synapse in the AVCN, but not the calyx of Held-principal cell synapse in the MNTB. In the present study, we have therefore also investigated the role of $I_{\mathrm{h}}$ in both AVCN bushy cells and MNTB principal neurons from normal and $d n / d n$ mice.

Finally, we have used a neuronal model based on our electrophysiological recordings to provide insight into how $I_{\mathrm{h}}$ contributes to synaptic integration and cell excitability in MNTB neurons in both normal and deaf mice.

\section{Materials and methods}

\section{Electrophysiology}

Normal (CBA, 12-14 days postnatal) and congenitally deaf $(d n / d n$ with CBA background, 12-14 days postnatal) mice were decapitated according to the Australian National University Animal Ethics Committee protocol. The forebrain and cerebellum were removed 
and placed in ice-cold low-calcium ACSF (in mM: NaCl, 130; KCl, 3.0; $\mathrm{MgCl}_{2}, 5.0 ; \mathrm{CaCl}_{2}, 1.0 ; \mathrm{NaH}_{2} \mathrm{PO}_{4}, 1.25 ; \mathrm{NaHCO}_{3}, 26.2$; and glucose, 10; equilibrated with $95 \% \mathrm{O}_{2}, 5 \% \mathrm{CO}_{2}$ ). Transverse slices $(150 \mu \mathrm{m})$ were made of the MNTB and AVCN using an EMS (EMS, Hatfield, USA) oscillating tissue slicer. Slices were incubated for $1 \mathrm{~h}$ in normal ACSF (in mM: $\mathrm{NaCl}, 130 ; \mathrm{KCl}, 3.0 ; \mathrm{Mg}_{2} \mathrm{SO}_{4}$, 1.3; $\mathrm{CaCl}_{2}, 2.0 ; \mathrm{NaH}_{2} \mathrm{PO}_{4}, 1.25 ; \mathrm{NaHCO}_{3}, 26.2$; and glucose, 10; equilibrated with $95 \% \mathrm{O}_{2}, 5 \% \mathrm{CO}_{2}$ ) at $35{ }^{\circ} \mathrm{C}$ and subsequently held at room temperature $\left(22-25^{\circ} \mathrm{C}\right)$ for electrophysiological recording. AVCN bushy cells were verified histologically by filling the cells with Alexa Fluor 488 (Molecular Probes, Eugene, USA).

Whole-cell current-clamp and voltage-clamp recordings from visualized MNTB and AVCN neurons were made using an Axopatch 1D, 200B or MultiClamp 700 A (Axon Instruments, Foster City, USA) connected to ITC-16 data acquisition cards (Instrutech, Long Island, USA) and Axograph data acquisition and analysis software. Analysis was also performed using Matlab R13 (Mathworks). Access resistance was routinely compensated by $>80 \%$.

\section{$\mathrm{I}_{h}$ current measurements and analysis}

Patch electrodes for current-clamp and voltage-clamp recordings contained (in $\mathrm{mM}$ ): Kgluconate, $122.5 ; \mathrm{KCl}, 17.5 ; \mathrm{NaCl}, 9 ; \mathrm{MgCl}_{2}, 1$; HEPES, 10; Mg-ATP, 3; GTP-Tris, 0.3; and EGTA, 0.2. The pH was adjusted to 7.2 using $\mathrm{KOH}$, and the osmolarity, when necessary, adjusted to 290-300 mOsm with sorbitol. Electrode resistance averaged 4.5 $\mathrm{M} \Omega$ and series resistance $<10 \mathrm{M} \Omega$. For voltage-clamp experiments examining $I_{\mathrm{h}}$, the following drugs were added to the perfusate: $1 \mu \mathrm{M}$ tetrodotoxin (TTX), $50 \mu \mathrm{M}$ 4-aminopyridine and $200 \mu \mathrm{M} \mathrm{CdCl}_{2}$. $I_{\mathrm{h}}$ was identified by adding $10 \mu \mathrm{M}$ of the specific $\mathrm{HCN}$ channel blocker ZD7288 (Tocris, MO, USA). The protocol for applying voltage steps was as follows: the cell was held at a potential of $-60 \mathrm{mV}$, and was stepped to membrane potentials from $-60 \mathrm{mV}$ to $-130 \mathrm{mV}$ ( $5 \mathrm{mV}$ decrements) for $1-\mathrm{s}$ duration (except for steps to $-130 \mathrm{mV}$ and $-120 \mathrm{mV}$ which were $0.5 \mathrm{~s}$ ) for MNTB and $-60 \mathrm{mV}$ to $-132 \mathrm{mV}$ (500 ms, 8-mV decrements) for AVCN. TTX and alpha-DTX were obtained from Alomone Laboratories (Jerusalem, Israel). Drugs were applied for $15 \mathrm{~min}$ before measurements were used in the analysis.

\section{Dynamic clamp experiments}

In order to analyse how $I_{\mathrm{h}}$ and DTX-sensitive low-threshold $\mathrm{K}^{+}$ currents contribute to the cell excitability, we simulated a lowthreshold voltage-dependent $\mathrm{K}^{+}$current using the Real Time Application Interface for Linux-based (RTAI: http://www.rtai.org) dynamic clamp (Dorval et al., 2001). Two computers were used, one for data acquisition running Axograph $Æ$ and a second 'dynamic-clamp' computer that reads voltage data samples from the patch-clamp amplifier and generates current commands in real-time every $100 \mu \mathrm{s}$. The 'dynamic-clamp' computer is an x86 architecture computer (Pentium 4, Intel, Santa Clara, USA) with a PCI-6036E data acquisition card (National Instruments, Austin, USA) for reading voltage and generating current commands to the clamped cell. The real-time dynamic clamp software was written (by R. Leao) using GNU-C (http://www.gnu.org) and routines for the data acquisition card were programmed using the Linux Control and Measurement Device Interface (COMEDI: http://www.comedi.org). Low-threshold $\mathrm{K}^{+}$currents were modelled as described in the next subsection. In these experiments, cells were bathed in ACSF containing $100 \mathrm{nM}$ alpha-DTX with or without ZD7288.

\section{Hodgkin-Huxley MNTB neuron model}

A single-compartment model of an MNTB neuron was constructed, incorporating a $\mathrm{Na}^{+}$current, low- and high-threshold voltage-activated $\mathrm{K}^{+}$currents, $I_{\mathrm{h}}$ and a leakage current.

Membrane currents were described using classical Hodgkin and Huxley equations. Channel conductance and currents followed the relationship

$$
I=\bar{g} a^{\lambda} b\left(V-V_{\mathrm{r}}\right), \text { where } a=m, n, o \text { or } u, \text { and } b=h
$$

where $\bar{g}$ is the maximum conductance, $a$ is the activation variable of $\lambda^{\text {th }}$ order, $b$ is the inactivation variable and $V_{\mathrm{r}}$ is the reversal potential. Changes in $a$ and $b$ were governed by the differential equation

$$
\mathrm{d} x / \mathrm{d} t=\left(x_{\infty}-x\right) / \tau_{\mathrm{x}}, \text { where } x=a \text { or } b
$$

where $x_{\infty}$ is the steady-state value and $\tau_{\mathrm{x}}$ is the time constant. Steadystate variables are described by opening and closing rate constants $\alpha$ and $\beta$. Opening and closing rating constants were described for $m, n, o$ as:

$$
\alpha=C_{\alpha}\left(V+V_{\mathrm{c}}\right) /\left(\mathrm{e}^{\frac{-\left(V+V_{\mathrm{c}}\right)}{V_{\alpha}}}-1\right) \text { and } \beta=C_{\beta} \mathrm{e}^{-\left(V-V_{\mathrm{c}}\right) / V_{\beta}}
$$

and for $\mathrm{u}$ as:

$$
\alpha=C_{\alpha} \mathrm{e}^{-\left(V-V_{\mathrm{c}}\right) / V_{\alpha}} \text { and } \beta=C_{\beta} /\left(\mathrm{e}^{-\left(V+V_{\mathrm{c}}\right) / V_{\beta}}-1\right)
$$

and for $h$ as $\alpha=0.007 \mathrm{e}^{(V+60) / 20}$ and $\beta=1 /\left(1+\mathrm{e}^{(V+30) / 10}\right)$.

For the $\mathrm{K}^{+}$currents and $I_{h}$, the values of $C_{\alpha}, C_{\beta}, V_{\alpha}, V_{\beta}$ and $V_{\mathrm{c}}$ were obtained by fitting the equation $x_{\infty}=\alpha /(\alpha+\beta)$ to Boltzmann relationships $(g / \bar{g}$ vs. $V)$ and/or to the relationship of activation and deactivation time constants to voltage (constant values for normal and deaf mouse cell models are shown in Table 1).

Voltage-gated currents consisted of a $\mathrm{Na}\left(I_{\mathrm{Na}}\right)$ current $\left(\bar{g}=\bar{g}_{\mathrm{Na}} ; a=m ; \lambda=3 ; b=h ; V_{\mathrm{r}}=V_{\mathrm{Na}}\right)$, two $\mathrm{K} \quad$ currents $\left(I_{\mathrm{TEA}}\right.$ and $\left.I_{\mathrm{DTX}}\right)$, a high-threshold TEA-sensitive current $\left(\bar{g}=\bar{g}_{\text {TEA }} ; a=n ; \lambda=4 ; b=1 ; V_{\mathrm{r}}=V_{\mathrm{K}}\right)$ and a low-threshold DTX-sensitive current $\left(\bar{g}=\bar{g}_{\text {DTX }} ; a=o ; \lambda=3 ; b=1 ; V_{\mathrm{r}}=V_{\mathrm{K}}\right)$ and a hyperpolarization-activated current $\left(\bar{g}=\bar{g}_{\mathrm{h}} ; a=u ; \lambda=1\right.$; $\left.b=1 ; V_{\mathrm{r}}=V_{\mathrm{Ih}}\right)$. Conductance values for normal and deaf models are shown in Table 2. The membrane voltage was modelled according to:

$$
\mathrm{d} V / \mathrm{d} t=\left(I_{\mathrm{Na}}+I_{\mathrm{DTX}}+I_{\mathrm{TEA}}+I_{\mathrm{h}}+I_{\mathrm{L}}+I_{\mathrm{Syn}}+I_{\mathrm{ST}}\right) / c,
$$

with $c$ equal to cell capacitance, and $I_{\mathrm{ST}}$ equal to the injected current, leakage current $I_{\mathrm{L}}=g_{\mathrm{L}}\left(V-V_{\mathrm{L}}\right)$ and synaptic currents equal to $I_{\text {Syn }}=\bar{g}_{\text {Syn }} A\left(V-V_{\text {Syn }}\right) \cdot \bar{g}_{\text {Syn }}$ is the maximum synaptic conductance (50 $\mathrm{nS}$ for IPSCs and EPSCs), $V_{\text {Syn }}$ is the reversal potential for the synaptic current ( $-90 \mathrm{mV}$ for IPSCs and $+60 \mathrm{mV}$ for EPSCs) and $A$ is the activation and deactivation variable equal to:

TABLE 1. Values of the model parameters used for Fig. 5, based on our experimental results

\begin{tabular}{lclcccc}
\hline & $m$ & $n$ & $o_{\text {Normal }}$ & $o_{\text {Deaf }}$ & $u_{\text {Normal }}$ & $u_{\text {Deaf }}$ \\
\hline$C_{\alpha}$ & -0.1 & -0.0344 & -0.019 & -0.0236 & 0.001 & 0.001 \\
$C_{\beta}$ & 0.5 & 0.9164 & 0.2314 & 0.2214 & 0.021 & 0.012 \\
$V_{\alpha}$ & 1 & $2 \times 10^{-6}$ & 0.1 & 0.1 & 10 & 26 \\
$V_{\beta}$ & 20 & 0.17 & 43.65 & 39.65 & 0 & 28 \\
$V_{\mathrm{c}}$ & 49 & 40.6 & 55.32 & 49.97 & 70 & 80 \\
\hline
\end{tabular}


TABLE 2. Conductance values of the model parameters used for Fig. 5, based on our experimental results

\begin{tabular}{lcc}
\hline & Normal $(\mathrm{nS})$ & Deaf $(\mathrm{nS})$ \\
\hline $\bar{g}_{\text {Na }}$ & 267 & 272 \\
$\bar{g}_{\text {TEA }}$ & 45 & 0.5 \\
$\bar{g}_{\text {DTX }}$ & 10.11 & 8.01 \\
$\bar{g}_{\text {h }}$ & 2.12 & 3.282 \\
$g_{\mathrm{L}}$ & 0.5 & 0.5 \\
\hline
\end{tabular}

$$
\mathrm{e}^{-\tau_{\mathrm{d}}\left(t-t_{\mathrm{ON}}\right)}\left(1-\mathrm{e}^{-\tau_{\mathrm{r}}\left(t-t_{\mathrm{ON}}\right)}\right)
$$

$\tau_{\mathrm{d}}$ is the decay time, $\tau_{\mathrm{r}}$ the rise time and $t_{\mathrm{ON}}$ the time when the postsynaptic currents occur.

\section{Results}

Whole-cell patch-clamp recordings were made from neurons visually located in the MNTB and AVCN of 12-14-day-old normal and deaf mice.

\section{Firing patterns in response to current injection and the role of $\mathrm{I}_{h}$ in MNTB neurons}

In order to measure the firing properties of principal cells, 800-ms positive and negative current steps were injected into MNTB neurons of normal and deaf mice, using whole-cell patch current-clamp recording. Normal MNTB principal cells typically respond with one to five action potentials (APs; mean 1.7) at the onset of positive current injection and remain silent for the remainder of the pulse (Fig. 1A,
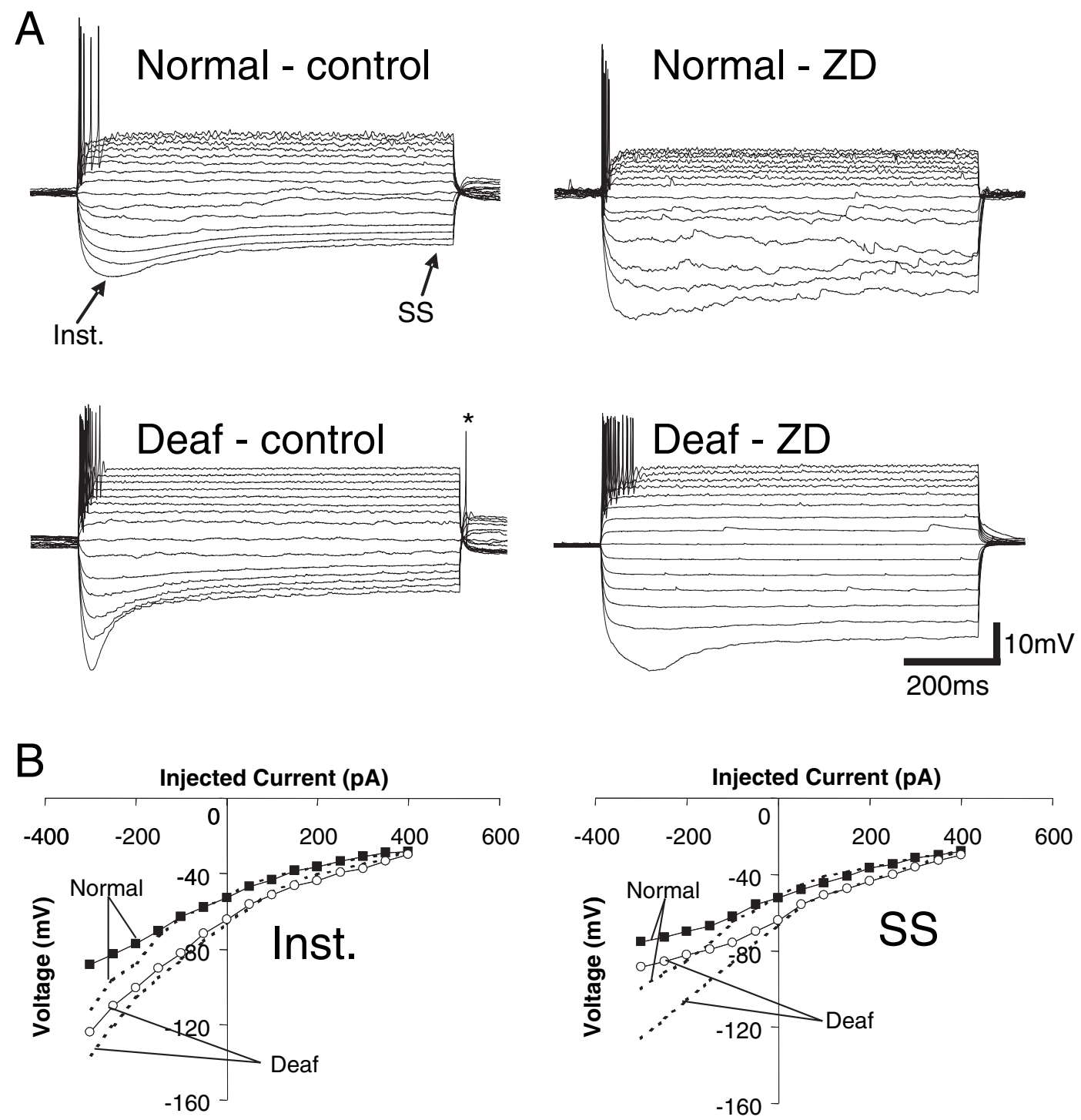

FIG. 1. Voltage response of MNTB neurons to current injection and block of $I_{\mathrm{h}}$ are different for normal and deaf mice. (A) Left, examples of voltage responses to current steps varying from -300 to $+400 \mathrm{pA}$ of MNTB neurons in normal and deaf mice. MNTB neurons from deaf mice typically fired several APs in response to positive current steps and displayed rebound APs $(*)$ at the end of negative current steps, while normal mice neurons invariably displayed a maximum of three APs in response to positive current steps and invariably did not exhibit rebound APs. Right, application of ZD7288 increased input resistance in normal and deaf mice and abolished rebound APs in deaf mice. (B) $I-V$ relationships for the individual cells shown in A, for instantaneous (Inst.) voltages (left panel) and steady-state (SS) voltages (right panel) measured at the beginning of and $\approx 790 \mathrm{~ms}$ after the onset of the current steps, respectively. Dashed lines show the effect of ZD7288 on the $I-V$ relationships. 
upper left panel). In contrast, neurons from deaf mice respond with repetitive firing to positive current injection (Fig. 1A, lower left panel; see also Leao et al., 2004). A relatively small after-hyperpolarization (AHP) at the end of positive current steps was observed in principal cells from normal mice. A more prominent AHP was observed in most of the neurons from deaf mice ( 22 of 24 cells). No neurons from normal mice showed rebound APs ( 0 of 24 cells), while the majority of neurons in deaf mice ( 20 of 24 cells) fired rebound APs at the end of negative current steps. Addition of the $I_{\mathrm{h}}$ channel blocker ZD7288 eliminated the rebound AP following a hyperpolarizing pulse in all 20 cells (of 24) that displayed rebound APs in $d n / d n$ mice.

Peak $I-V$ relationships were determined for MNTB neurons from normal and deaf mice (excluding the initial region of action potentials following depolarizing current injection). Steady-state voltages were measured at the end of the current step $(790 \mathrm{~ms})$. As illustrated in Fig. 1B, both peak and steady-state $I-V$ relationships were much steeper in MNTB neurons from deaf mice than from normal mice. The resting membrane potential of MNTB neurons was not statistically different between normal and deaf mice (normal, $-67 \pm 3 \mathrm{mV}$, $n=42$; deaf, $-68 \pm 4 \mathrm{mV}, n=42 ; P>0.1$ ). There was no significant difference in input resistance at $-60 \mathrm{mV}$ between deaf and normal mice (normal, $225 \pm 10 \mathrm{M} \Omega, n=9$; deaf, $204 \pm 9 \mathrm{M} \Omega$, $n=9 ; P>0.05)$. Addition of ZD7288 to the bath caused input resistance at $-60 \mathrm{mV}$ to increase by $21 \%$ in deaf mice (from $204 \pm 9$ to $247 \pm 14 \mathrm{M} \Omega ; n=9, P<0.05$ ) and $9 \%$ in normal mice (from $225 \pm 10$ to $247 \pm 13 \mathrm{M} \Omega ; n=10, P>0.05)$. Resting membrane potential decreased by $1 \pm 0.5 \mathrm{mV}$ in normal mice $(P>0.05)$ and $4 \pm 0.7 \mathrm{mV}$ in deaf mice $(P=0.05)$ following addition of ZD7288. The firing pattern did not alter significantly after ZD7288 addition in neurons from normal mice. However, cells from deaf mice showed a diverse behaviour in response to positive current steps; five cells increased their firing frequency $(15.5 \pm 2$ to $19.8 \pm 1$ APs, $P<0.05)$, six cells decreased their firing frequency (18.72 to $14.1 \pm 1$ APs, $P<0.05)$ and 13 cells had no alteration in their firing pattern.

\section{$\mathrm{I}_{h}$ currents were larger in MNTB neurons from deaf mice}

Voltage-clamp recordings were used to investigate both the amplitude and kinetics of $I_{\mathrm{h}}$ in MNTB principal cells from normal and deaf mice (Fig. 2). Voltage steps ( 1 or $0.5 \mathrm{~s}$ ) to potentials ranging from -60 to $-130 \mathrm{mV}$ were applied with and without $10 \mu \mathrm{M}$ ZD7288 in the bath. Steady-state currents were measured at $490 \mathrm{~ms}$ (voltage steps of 1-s duration were routinely used, but steps were restricted to $0.5 \mathrm{~s}$ at higher voltages, -120 to $-130 \mathrm{mV}$, to avoid membrane instability; hence, records are shown truncated to the same time in Fig. 2A and B for clarity of presentation). At $-130 \mathrm{mV}$, MNTB neurons from normal and deaf mice displayed significantly different whole-cell currents (normal, $-0.57 \pm 0.02 \mathrm{nA}, n=17$; deaf, $-0.75 \pm 0.01 \mathrm{nA}, n=19 ; P=0.01$; Fig. 2B). Addition of ZD7288 to the bath decreased currents in normal and deaf mice by $33 \pm 1$ and $42 \pm 2 \%$, respectively $(n=30, P<0.01)$. Reversal potentials for the ZD7288-sensitive currents were obtained by extrapolating the $I-V$ plots by fitting a first- or second-order polynomial to the $I-V$ relationships. The reversal potential for ZD7288-sensitive currents in MNTB neurons from deaf mice was $-44 \pm 5 \mathrm{mV}$ and from normal mice was $-46 \pm 5 \mathrm{mV}(n=20, P>0.5)$.

The $I_{\mathrm{h}}$ activation time course for MNTB neurons in both normal and deaf mice was well fitted by a single exponential function. Activation time constants were not significantly different for MNTB neurons from normal and deaf mice over the range of potentials tested (Fig. 2C). Tail currents were obtained following voltage steps (1-s duration) from -130 to $-60 \mathrm{mV}$ ( $-5-\mathrm{mV}$ increments). (It was only possible to obtain stable results using 1-s duration steps for voltages below $-120 \mathrm{mV}$ in the absence of ZD7288). Tail current amplitudes were larger in deaf mice than in normal mice ( $96 \pm 6$ vs. $64 \pm 6 \mathrm{pA}$; $n=20, P<0.01$; Fig. 2D). In order to obtain current activation parameters, a Boltzmann function of the form $I / I_{\min }=1 /\left(1+\mathrm{e}^{\left(V-V_{1 / 2}\right.}\right) /$ $k$ was fitted to the tail currents. Mean $V_{1 / 2}$ and $k$ did not differ significantly between normal and deaf mice (normal, $V_{1 / 2}=$ $-93 \pm 2 \mathrm{mV}, k=8 \pm 0.5 \mathrm{mV}$; deaf, $-96 \pm 1 \mathrm{mV}, k=9 \pm 0.5 \mathrm{mV}$; Fig. 2E).

\section{Temporal summation for EPSCs and IPSCs was decreased by $\mathrm{I}_{h}$ in deaf mice but not in normal mice}

EPSC- and IPSC-like currents were injected into MNTB neurons in order to assess temporal summation of excitatory and inhibitory inputs and provide some insight into the physiological role of $I_{\mathrm{h}}$ in these cells (Fig. 3). Rise time and decay time for the synaptic current waveforms were similar to AMPA- and glycine-mediated synaptic currents observed in MNTB neurons. Temporal summation was quantified by a summation factor [a percentage, equal to the peak of the last postsynaptic potential (PSP) divided by the peak of the first PSP]. ZD7288 was added to the bath to investigate the effect of $I_{\mathrm{h}}$ on temporal summation (Fig. 3).

Under control conditions EPSP and IPSP summation factors did not differ significantly between normal and deaf mice (EPSPs: normal, $118 \pm 4.5 \%$; deaf, $126 \pm 2 \%$; IPSPs: normal, $132 \pm 3.1 \%$; deaf, $134 \pm 1.8 \% ; n=17)$. Addition of ZD7288 did not significantly alter the summation factor for EPSPs in MNTB neurons from normal mice (control, $129 \pm 2.6 \%$; after ZD7288, $133 \pm 5.1 \%$ ). The summation factor for IPSPs was increased by $22.8 \%$ in MNTB neurons from normal mice (162 $\pm 5.7 \%$ after ZD7288 addition; $n=9, P=0.04)$. However, changes in MNTB neurons from deaf mice following ZD7288 were much more dramatic. The summation factor for EPSPs increased by $62.7 \%(n=8, P<0.05)$ and for IPSPs increased by $58.7 \%(n=8, P<0.05)$ after addition of ZD7288. Further addition of DTX caused no significant changes in the summation factor for IPSPs in either normal or deaf mice. However, DTX increased EPSP summation in normal (from $123 \pm 4.5 \%$ in the presence of ZD alone to $157 \pm 6 \%$ in the presence of ZD and DTX; $n=8, P<0.03$ ) but not in cells from deaf mice.

\section{AVCN bushy cells had similar firing properties and $\mathrm{I}_{h}$ in normal and deaf mice}

Bushy cells in the AVCN of normal and deaf mice were investigated as a comparison to MNTB principal cells (Fig. 4). Cells were confirmed as bushy cells by intracellular labelling (Fig. 4D). Passive membrane properties did not differ significantly between normal and deaf mouse bushy cells. The resting membrane potentials of cells from normal and deaf mice were $-56 \pm 0.4(n=13)$ and $-55 \pm 0.7 \mathrm{mV}$ ( $n=8$; not significant), respectively. Input resistance was not significantly different for cells from normal and deaf mice (150 \pm 4 and $136 \pm 6 \mathrm{M} \Omega$, respectively). Whole-cell capacitance values were $21 \pm 0.4$ and $24 \pm 1 \mathrm{pF}$ for AVCN cells from normal and deaf mice, respectively (not significant). Firing properties of bushy cells from both normal and deaf mice were assessed using 200-ms current steps varying from -300 to $+400 \mathrm{pA}$ (50-pA steps) in normal ACSF. For depolarizing steps, the maximum number of APs was $2.3 \pm 0.1$ $(n=13)$ for normal mice and $2.0 \pm 0.1 \quad(n=8)$ for deaf mice $(P>0.05$; Fig. 4A). Membrane responses to hyperpolarizing steps did not differ between normal and deaf mice (Fig. 4B). In voltage clamp, 
A
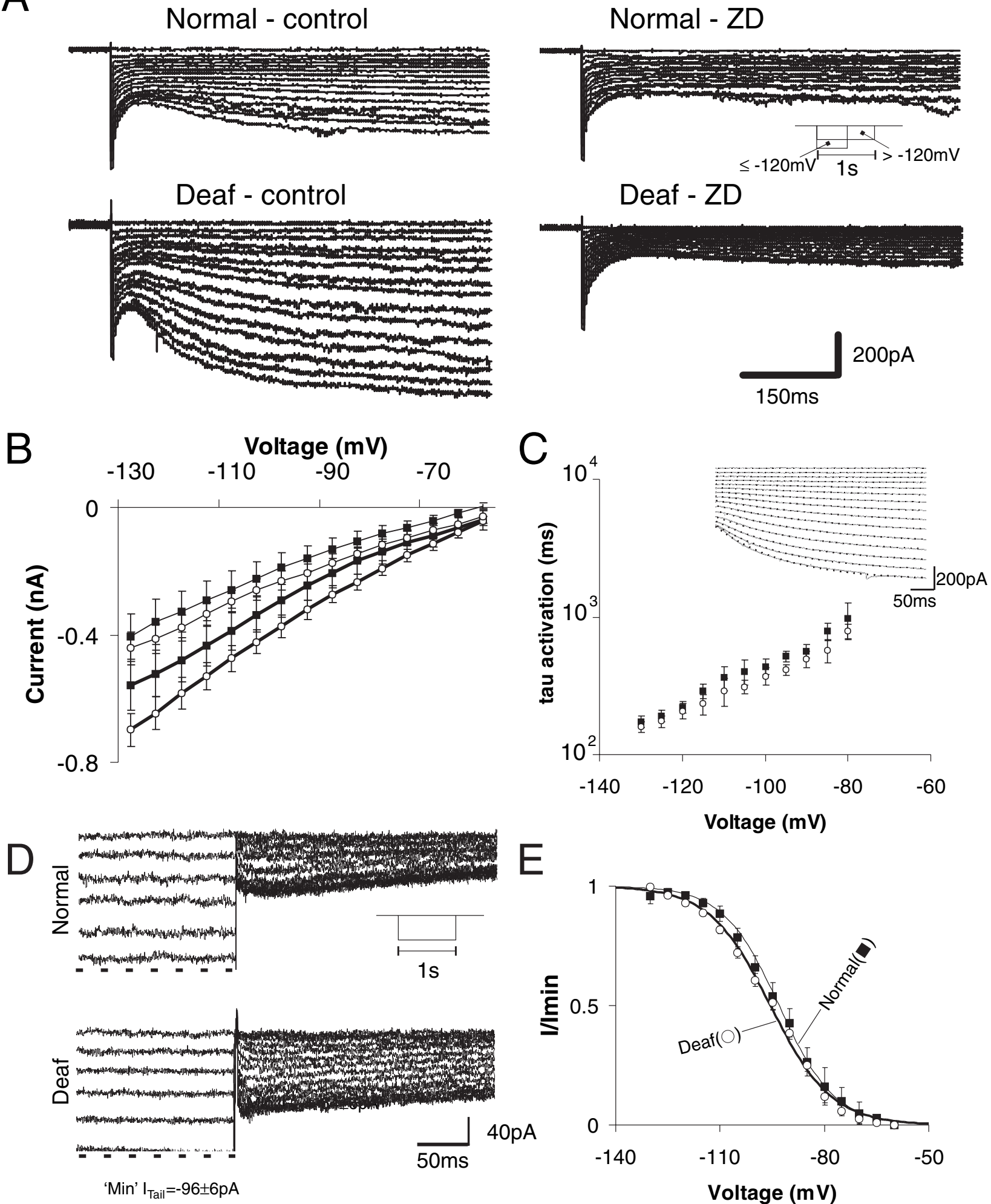

FIG. 2. Voltage-clamp responses to hyperpolarizing potentials were different for MNTB neurons from normal and deaf mice. (A) Examples of current responses of MNTB neurons from a normal (top) and a deaf (bottom) mouse to hyperpolarizing voltage steps ( -130 to $-60 \mathrm{mV}, 1 \mathrm{~s}$ duration except for steps more negative than $-120 \mathrm{mV}$ which were of $500 \mathrm{~ms}$ duration; see inset). Right panels show current responses of neurons from a normal (top) and a deaf (bottom) mouse after application of ZD7288. (B) Summary of $I-V$ relationships of MNTB neurons from normal $(\mathbf{\square})$ and deaf mice $(\bigcirc)$ in control (thick solid lines) and in $10 \mu \mathrm{M}$ ZD7288 (thin solid lines). (C) $I_{\mathrm{h}}$ activation kinetics did not differ significantly between normal $(\mathbf{\square})$ and deaf $(O)$ mice. $I_{\mathrm{h}}$ currents were fitted with single exponentials (dotted lines, inset). (D) Examples of tail currents following $1 \mathrm{~s}$ duration hyperpolarizing voltage steps (inset) obtained from a normal and a deaf mouse. (Dashed lines indicate that the larger currents during the 1-s steps cannot be shown due to the magnification of the tail currents.) (E) Summary of $I-V$ relationships from tail currents. $\mathbf{\square}$, data from normal mice; $\bigcirc$, data from deaf mice. Thin and thick solid lines show Boltzmann functions obtained by fitting mean $V_{1 / 2}$ and mean $k$ from normal and deaf mice, respectively. 

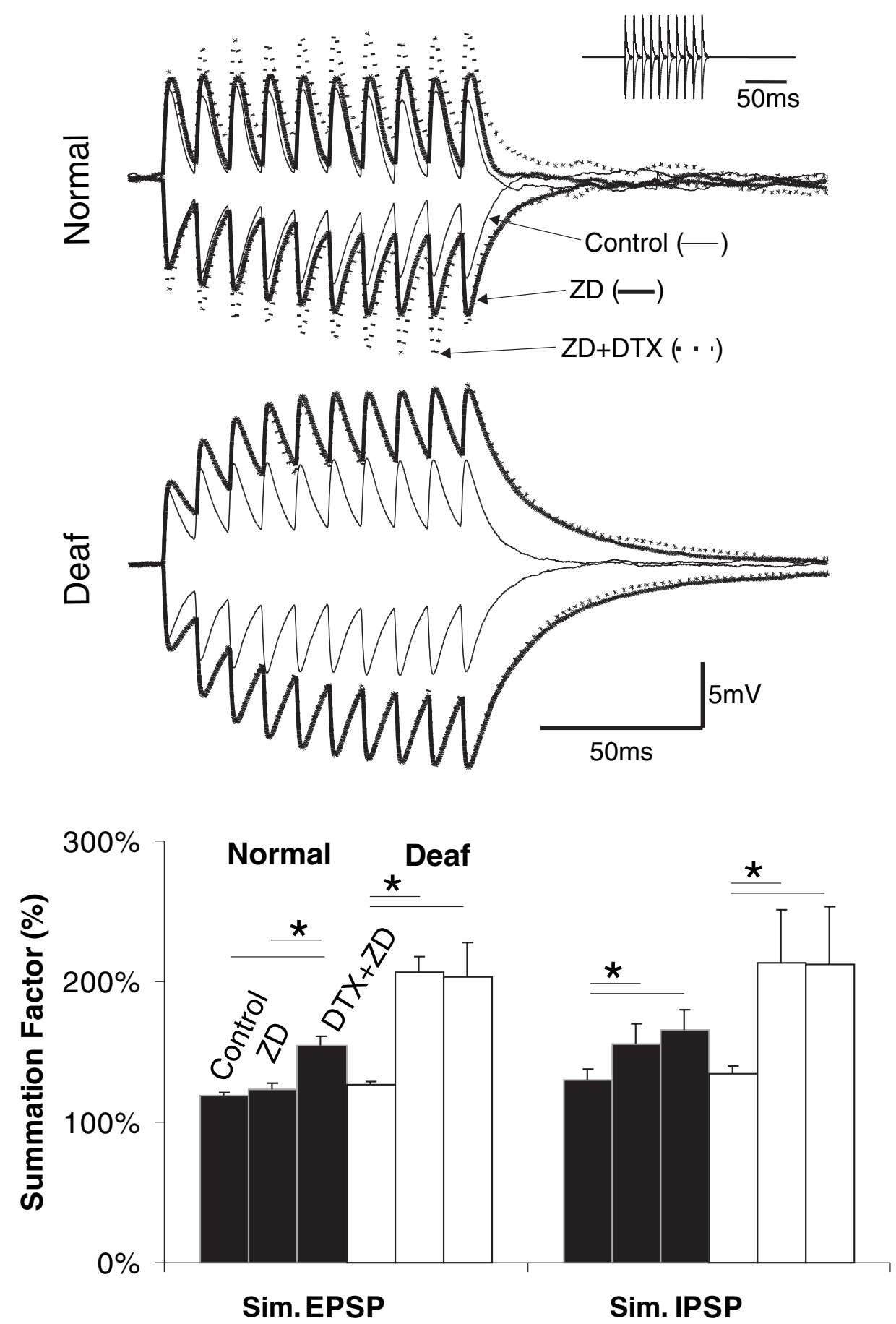

FIG. 3. Temporal summation was different in MNTB neurons from normal and deaf mice. (A) Example of voltage recorded in an MNTB neuron in response to current injections with time courses simulating trains of EPSCs and IPSCs (labelled 'Sim. EPSP' and 'Sim. IPSP' in B). Application of ZD7288 to the bath caused simulated EPSPs and IPSPs (solid traces; dotted traces represent control) to summate in a neuron from a deaf mouse. ZD7288 did not substantially increase simulated EPSP summation in a neuron from a normal mouse but did affect summation of simulated IPSPs. Further addition of alpha-DTX to the bath increased simulated EPSP summation in neurons from normal but not deaf mice. (B) Summary data showing the effect of ZD7288 and alpha-DTX on temporal summation (the summation factor is the ratio of the last simulated PSP amplitude over the first PSP amplitude); ${ }^{*} P<0.03$.

hyperpolarizing voltage steps over a range of potentials (-60 to $-132 \mathrm{mV}$ ) were used to assess the amplitude of hyperpolarizationactivated currents. Currents activated in the hyperpolarizing voltage range were similar between normal and deaf mice (Fig. 4C). Instantaneous and steady-state currents were measured at 5-10 ms and 490-495 $\mathrm{ms}$ from the beginning of the voltage step. Average steady-state currents for AVCN bushy cells in normal and deaf mice were $-913 \pm 31$ and $-772 \pm 60 \mathrm{pA}$, respectively $(P>0.05$; Fig. 4C). Tail-current parameters were similar for normal and deaf mice. Halfactivation voltages were $-101 \pm 0.8$ and $-101 \pm 0.7 \mathrm{mV}$ for deaf and normal mice, respectively; slope factors were $11 \pm 0.2 \mathrm{mV}$ (normal mice) and $10 \pm 0.1 \mathrm{mV}$ (deaf mice) and thresholds (potential required to elicit $5 \%$ of the total current) were $67.6 \pm 0.8$ and $73.6 \pm 0.9 \mathrm{mV}$ (not significant). 

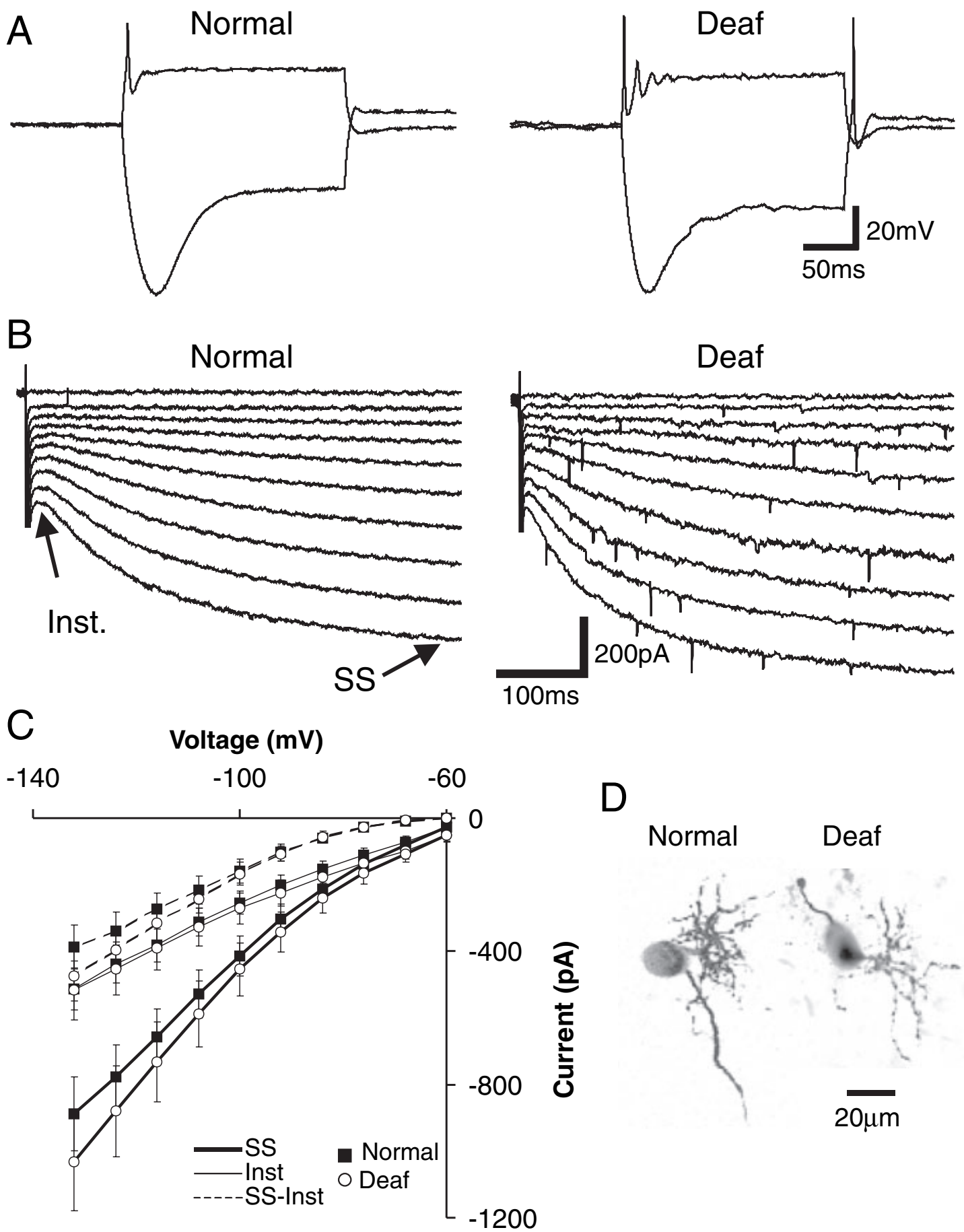

FIG. 4. AVCN bushy cells had similar firing pattern and hyperpolarization-activated currents in normal and deaf mice. (A) Current-clamp response of a bushy cell to polarizing current steps (-300 and $+200 \mathrm{pA}, 200 \mathrm{~ms}$ duration) in normal (left) and deaf (right) mice. (B) Examples of current responses of normal (left) and deaf (right) mice bushy cells to hyperpolarizing voltage steps. (C) Summary of $I-V$ relationships of bushy cells in normal ( $\mathbf{\square})$ and deaf $(O)$ mice. Thick solid lines represent steady-state (SS) currents (measured $\approx 490 \mathrm{~ms}$ after the start of the voltage step; see B), thin solid lines show instantaneous (Inst.) current responses and dashed lines represent the difference between SS and instantaneous currents. (D) Examples of two reconstructed bushy cells from normal and deaf mice showing the characteristic morphological features of bushy cells.

\section{$\mathrm{I}_{h}$ produced variable effects on the firing properties of MNTB neurons}

Following our observation, in MNTB neurons from deaf mice, of large variability in the effect of blocking $I_{\mathrm{h}}$ on AP firing during depolarizing current steps, we investigated the potential interaction between $I_{\mathrm{h}}$ and low-threshold voltage-dependent $\mathrm{K}^{+}$currents by examining the ratio of AP firing after and before the application of ZD7288, and plotting this ratio against the magnitude of the outward current (recorded at $-40 \mathrm{mV}$, stepping from $-60 \mathrm{mV}$ ). Figure 5A shows two examples of MNTB neurons from deaf mice which exhibited different firing properties under control conditions, and the effect of ZD7288 


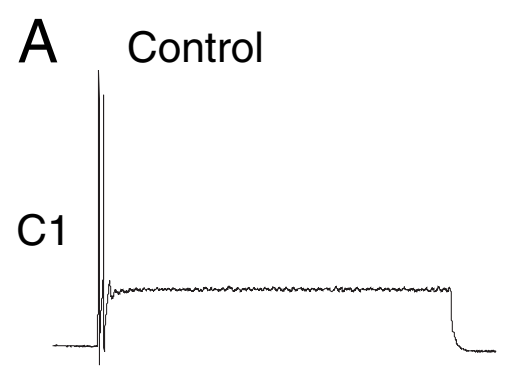

Control

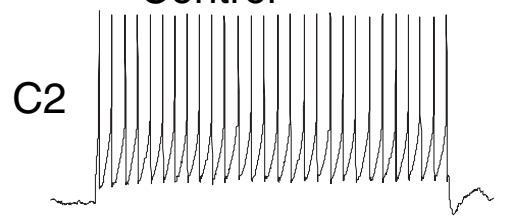

C
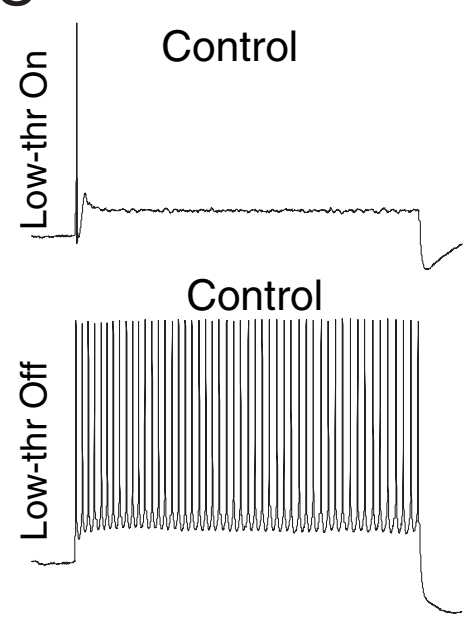

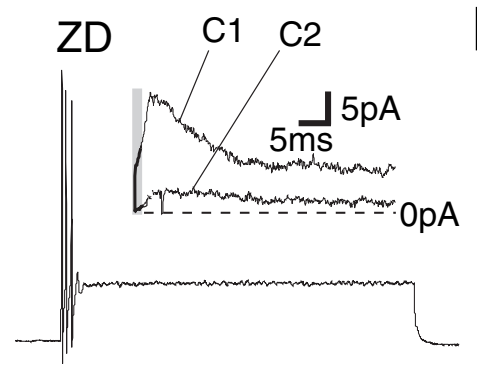

ZD

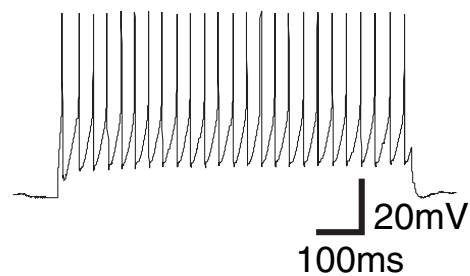

$100 \mathrm{~ms}$
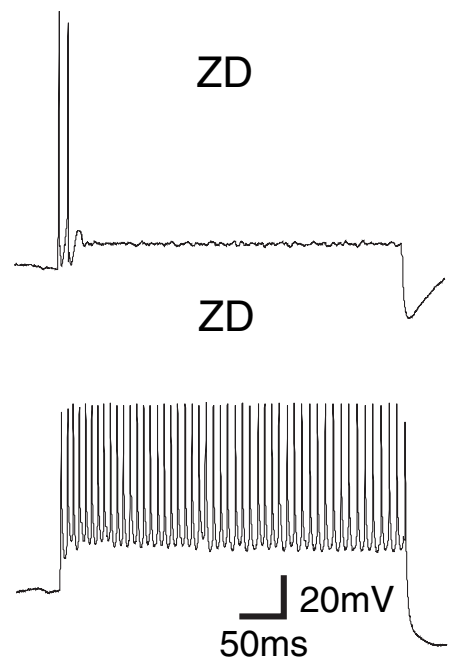

B

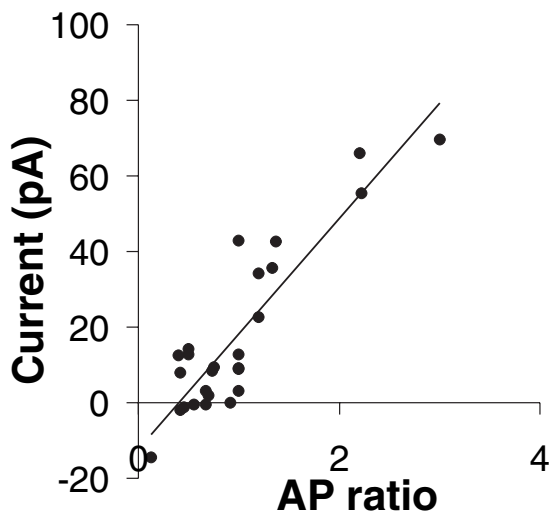

D

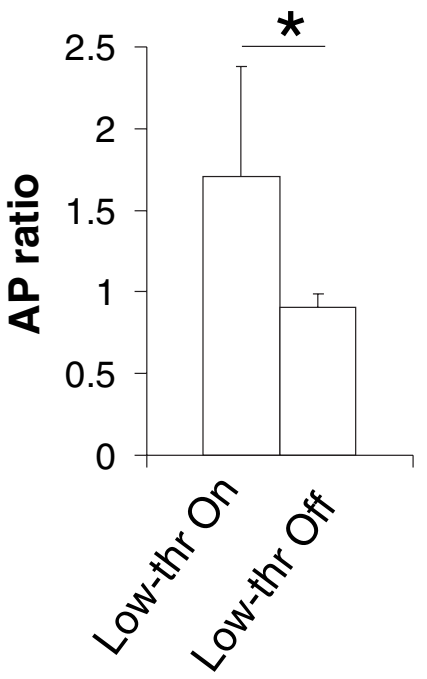

FIG. 5. $I_{\mathrm{h}}$ interacted with low-threshold voltage-dependent $\mathrm{K}^{+}$currents in modulating cell excitability. (A) Examples of two MNTB neurons from deaf mice with different responses to the application of ZD7288. The upper panels show the response of a cell (C1) to a 150-pA current injection before and after ZD7288 application. In voltage clamp, this cell displayed an outward current of $21 \mathrm{pA}$ (inset) at $-40 \mathrm{mV}$ (stepping from $-60 \mathrm{mV}$ ). The lower panels show the response of a different cell (C2) before and after application of ZD7288. In this cell, application of ZD7288 decreased the number of APs from 28 to 25 . Inset shows outward currents (leak subtracted) recorded at $-40 \mathrm{mV}$ for the two cells in the example (the grey rectangle shows where the capacitance artefacts were subtracted). (B) Relationship between the outward current at $-40 \mathrm{mV}$ and the ratio of the number of APs in the presence of ZD7288 and number of APs in control conditions (solid line shows a linear fit). (C) Effect of ZD7288 on the number of APs in response to a 150-pA current injection in an MNTB neuron from a deaf mouse in the presence of $100 \mathrm{~nm}$ alpha-DTX, in which low-threshold voltage-dependent $\mathrm{K}^{+}$currents (Low-thr) were mimicked by a dynamic clamp. Upper panels show the cell with the simulated low-threshold $\mathrm{K}^{+}$current active (Low-thr On) and lower panels show the same cell without the mimicked low-threshold currents (note that this cell fired 50 APs in control conditions and 48 APs in the presence of ZD7288). (D) Summary of the ratio of APs in the presence and absence of ZD7288 when Lowthr was 'On' and 'Off'.

application on the number of APs. One of the cells (C1) exhibited an increase in the number of APs following addition of ZD7288. This cell also exhibited a relatively large outward current following a voltageclamp step from -60 to $-40 \mathrm{mV}$ (Fig. 5A, inset). In contrast, C2 exhibited a decrease in the number of APs following addition of ZD7288 and was associated with a small outward current following the step to $-40 \mathrm{mV}$ in the presence of ZD7288 (Fig. 5A, inset). Figure $5 \mathrm{~B}$ shows a plot of the AP ratio vs. the magnitude of the current following a step from -60 to $-40 \mathrm{mV}$ (The AP ratio was calculated as the ratio of the number of APs elicited by a 150 -pA current step after and before the application of ZD7288. An AP ratio of $<1$ indicates a decrease in the number of APs following addition of ZD7288). As can be seen in Fig. 5B, there is a strong positive correlation between the change in firing induced by ZD7288 application and the amount of outward current recorded at $-40 \mathrm{mV}\left(r^{2}=0.8, P=0.002, n=26\right)$. The potential interaction between low-threshold $\mathrm{K}^{+}$currents and $I_{\mathrm{h}}$ was therefore investigated using a dynamic clamp to simulate lowthreshold voltage-dependent $\mathrm{K}^{+}$currents (in the presence of DTX). The results are illustrated in Fig. 5C and D. Dynamic clamp experiments (on deaf mice) MNTB neurons showed that, in the presence of a simulated low-threshold voltage-dependent $\mathrm{K}^{+}$current, blocking $I_{\mathrm{h}}$ resulted in an increased firing of cells from $2 \pm 0.8$ to $3.25 \pm 1$ APs (AP ratio $1.7 \pm 0.7 ; n=4, P=0.05$ ). In contrast, in the absence of the low-threshold $\mathrm{K}^{+}$current, ZD7288 caused the opposite effect, decreasing firing from $77.7 \pm 34$ to $68 \pm 21$ APs (AP ratio $0.9 \pm 0.1, n=4, P=0.05$; Fig. $5 \mathrm{C}$ and $\mathrm{D}$ ). 
MNTB cell model replicated the difference between MNTB neurons in normal and deaf mice

A Hodgkin-Huxley model (see Materials and methods) of MNTB neurons was used to provide insight into the differences in firing patterns and temporal summation of transient potentials in deaf and normal mice (Fig. 6). The model, which incorporates the measured differences in membrane currents, including $I_{\mathrm{h}}$, reproduced the firing patterns observed experimentally in both groups. Figure 6A (thin traces) illustrates the responses to a 200-pA depolarizing current step, showing the typical single action potential in cells from normal mice and multiple firing in cells from deaf mice. The thick traces show the
A

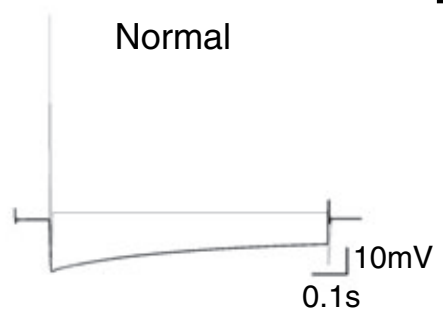

Deaf
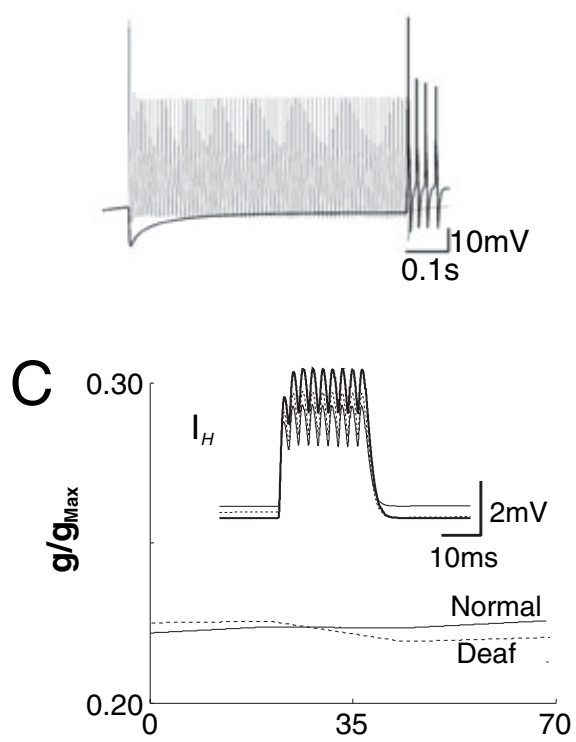

0.15

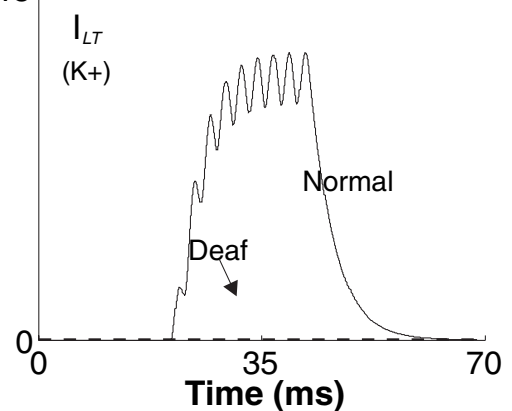

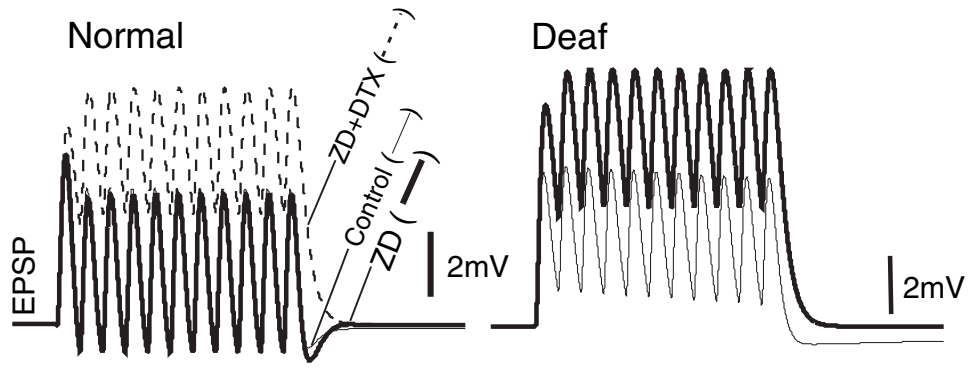
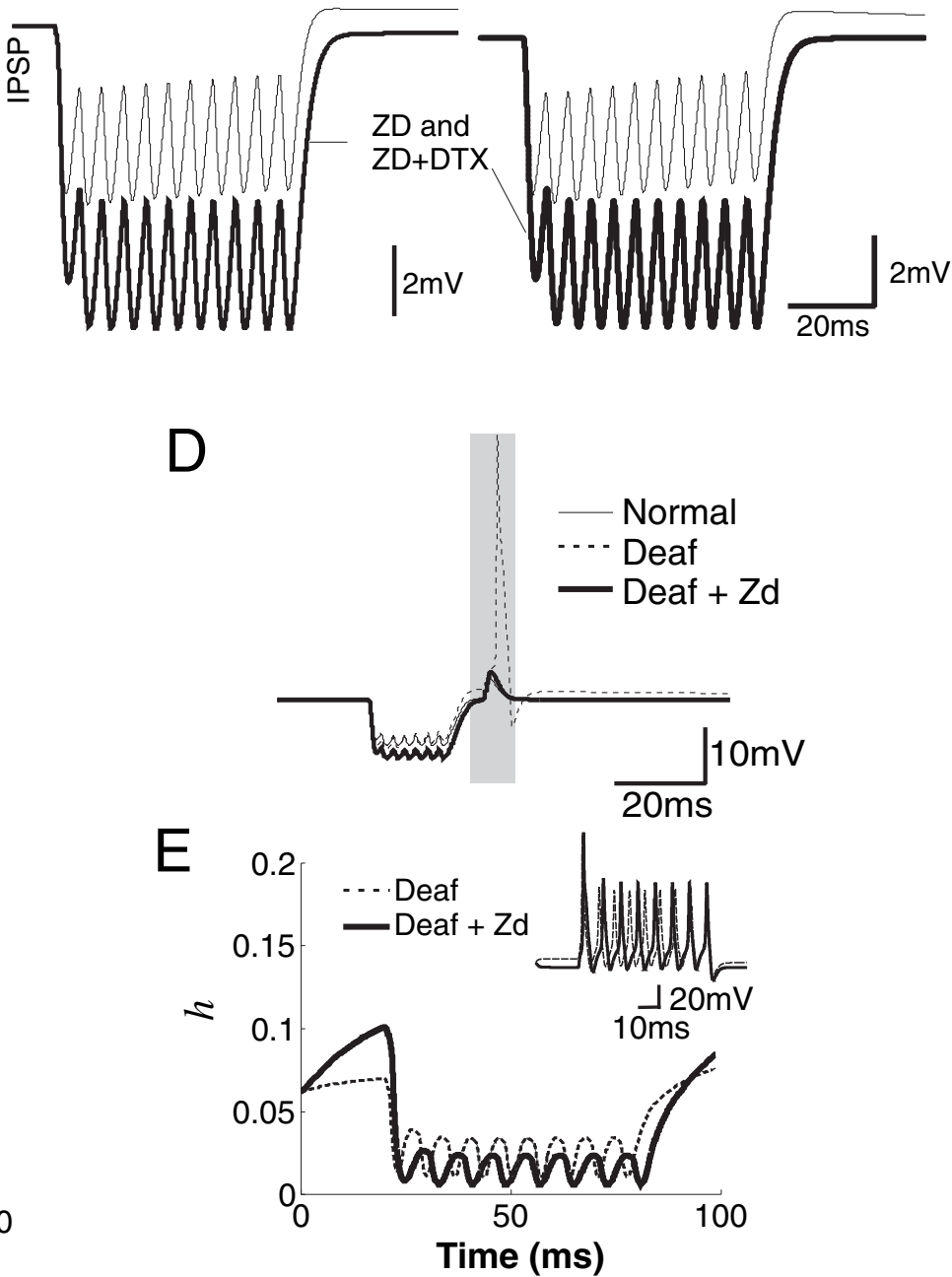

FIG. 6. MNTB membrane model replicates the difference between MNTB neurons from normal and deaf mice. (A) An Hodgkin-Huxley (HH) model derived from MNTB neurons of deaf and normal mice reproduced the firing patterns observed experimentally in both groups. Thin traces show the responses to a 200-pA current step, thick traces show the same cell's response to a -100-pA hyperpolarization step. (B) Model response to simulated EPSC and IPSC trains. To model ZD7288 application $I_{\mathrm{h}}$ conductance was set to zero and, for ZD7288 + alpha-DTX, both $I_{\mathrm{h}}$ and the low-threshold voltage-dependent $\mathrm{K}^{+}$conductance were set to zero (see Materials and methods for details of model). (C) $I_{\mathrm{h}}$ model response (top) during a subthreshold train of simulated EPSPs (inset). The deaf mouse model (dashed line) displays larger deactivation than the normal mice model (solid line). The inset shows simulated EPSPs from the normal mouse model (thin solid line), deaf mouse model (dashed line) and deaf mouse without $I_{\mathrm{h}}$ (thick solid line). Bottom, low-threshold voltage-dependent potassium currents responses for the same simulated EPSPs. (D) Subthreshold simulated EPSP caused a rebound AP following a train of simulated IPSPs in the deaf mouse model (dashed line) but not in the normal mouse model (solid line). The grey area is the time window during which the EPSP was able to elicit an AP. (E) Na ${ }^{+}$current inactivation state $(h)$ for the model responses to a 200-pA current injection with (Deaf) and without (Deaf $+\mathrm{ZD}$ ) $I_{\mathrm{h}}$. Inset, Deaf cell model response to a 200-pA current step with and without $I_{\mathrm{h}}$. 
same cells' response to a $-100-p A$ hyperpolarization step, which results in rebound firing of the deaf mouse model cell. Figure $6 \mathrm{~B}$ illustrates the model cells' responses to simulated EPSC- and IPSClike trains. To model ZD7288 application $I_{\mathrm{h}}$ conductance was set to zero and, for ZD7288 + alpha-DTX, both $I_{\mathrm{h}}$ and the low-threshold voltage-dependent $\mathrm{K}^{+}$conductance were set to zero (see Materials and methods for details of the model). Figure $6 \mathrm{C}$ illustrates the model responses (top) during a train of subthreshold EPSP-like transients (inset). The deaf mouse model (dashed line) displays a larger deactivation than the normal mouse model (solid line). The inset shows simulated EPSPs from the normal mouse model (thin solid line), the deaf mouse model (dashed line) and the deaf mouse model without $I_{\mathrm{h}}$ (thick solid line). Figure 6C (lower plot) illustrates the lowthreshold voltage-dependent potassium currents responses for the same simulated EPSPs. Figure 6D shows that the model predicts that a subthreshold EPSP is more likely to cause a rebound action potential following a train of IPSPs in the deaf mouse model (dashed line) than in the normal mouse model (solid line). The grey area is the time window in which the simulated EPSP is able to elicit an AP.

In order to investigate the possibility that the presence of $I_{\mathrm{h}}$ could partially prevent $\mathrm{Na}^{+}$current inactivation, we analysed the $h$ state (inactivation) of the modelled $\mathrm{Na}^{+}$conductance $\left(\bar{g}_{\mathrm{Na}} m^{3} h\right)$ in the deaf mouse cell model. Without $I_{\mathrm{h}}$, the $\mathrm{Na}^{+}$current inactivation state $h$ was closer to zero (causing greater $\mathrm{Na}^{+}$current inactivation) than the model with $I_{\mathrm{h}}$ (Fig. 6E).

\section{Discussion}

Previous studies of auditory brainstem neurons have highlighted the importance of $I_{\mathrm{h}}$ in determining the resting membrane properties (input resistance and membrane potential) and firing characteristics of particular cell types (Banks et al., 1993; Kandler \& Friauf, 1995; Bal \& Oertel, 2000; Cuttle et al., 2001; Koch \& Grothe, 2003). Shaikh \& Finlayson (2003) have shown directly using in vivo recordings in rats that $I_{\mathrm{h}}$ in superior olivary complex neurons affects cell excitability. Neurons which exhibit a substantial $I_{\mathrm{h}}$ have a lower input resistance, which improves temporal responses to synaptic input and reduces temporal summation of synaptic input trains. However, $I_{\mathrm{h}}$ may also cause rebound depolarization and/or spiking (Koch \& Grothe, 2003). Although a role for rebound spiking in auditory processing has been proposed (Casseday et al., 1994), it would be an undesirable property for a neuron which follows synaptic input with high temporal precision. In the present study, we have demonstrated the existence of a small $I_{\mathrm{h}}$ current in MNTB neurons from normal mice. However, in congenitally deaf mice there is a much stronger $I_{\mathrm{h}}$ contribution which dramatically affects the integrative properties of MNTB neurons. In contrast to MNTB neurons, the properties of AVCN bushy cells are not different in $d n / d n$ mice. Interestingly, the endbulb of Held-bushy cell connection is different in the AVCN of $d n / d n$ mice, whereas the calyx of Held-principal cell synapse in the MNTB is the same in deaf and normal mice (Oleskevich et al., 2004).

The difference in the amplitude of $I_{\mathrm{h}}$ currents recorded in MNTB neurons from normal and deaf mice is sufficient to account for the differences in integrative properties and rebound APs observed in current-clamp recordings in these neurons. A much greater variability in the firing responses of MNTB neurons to injected current following $I_{\mathrm{h}}$ block was observed in deaf mice. This variability could reflect a lack of regulation of $I_{\mathrm{h}}$ channel expression in deaf mice, involving different subcellular localization of hyperpolarization-activated cyclic nucleotide gated $(\mathrm{HCN})$ channels and/or different $\mathrm{HCN}$ channel subunits in different neurons (Santoro \& Baram, 2003). For example, previous studies have suggested that dendritic $I_{\mathrm{h}}$ decreases neuronal excitability while somatic $I_{\mathrm{h}}$ increases excitability (Santoro \& Baram, 2003). Diverse HCN channel subunit expression could also promote variable firing behaviour. In the neocortex, expression of HCN1 causes hyperexcitability while other HCN subunits do not change neuronal firing properties (Strauss et al., 2004). However, it is likely that complex interactions between $I_{\mathrm{h}}$ and $\mathrm{K}^{+}$currents are primarily responsible for the mosaic of responses observed here. Our results demonstrate a correlation between the change in firing to injected current following block of $I_{\mathrm{h}}$ and the magnitude of the outward current following a depolarizing step, suggesting that the variability in response from cell to cell is related to the relative contributions of $I_{\mathrm{h}}$ and low-threshold $\mathrm{K}^{+}$currents. In addition, our modelling results indicate that $\mathrm{Na}^{+}$channel inactivation may play a role (Fig. 6). The interplay between $I_{\mathrm{h}}$, low-threshold $\mathrm{K}^{+}$currents and $\mathrm{Na}^{+}$currents results in a variable effect of blocking $I_{\mathrm{h}}$ on the response to injected current, depending on the relative magnitude of each of these currents. However, despite the variability in responses, our results show that there is a significant overall enhancement of $I_{\mathrm{h}}$ in MNTB neurons from deaf mice, which is likely to affect the integration of synaptic potentials in these neurons. The role of $I_{\mathrm{h}}$ in temporal integration of synaptic inputs is demonstrated in our experimental and modelling results (see also Koch \& Grothe, 2003). Blocking $I_{\mathrm{h}}$ currents with ZD7288 has little effect on temporal summation of EPSP- and IPSPlike transients in MNTB neurons from normal mice but a large effect in MNTB neurons from deaf mice. Modelling shows that the experimentally measured difference in $I_{\mathrm{h}}$ is sufficient to explain this significant difference. Modelling also shows that activation of $I_{\mathrm{h}}$ during trains of IPSPs can significantly alter the cells response to EPSPs. A larger amplitude $I_{\mathrm{h}}$ was found to render the cell more excitable in the period immediately following a train of IPSPs.

A previous study in rat MNTB suggested that $I_{\mathrm{h}}$ is important in setting the resting membrane potential and input resistance in order to indirectly control low-threshold potassium currents (Banks et al., 1993). Our results show that $I_{\mathrm{h}}$ has a modest role in setting resting membrane potential and input resistance in normal mice, although $I_{\mathrm{h}}$ is larger in MNTB neurons from deaf mice. Differences in $I_{\mathrm{h}}$ amplitude could be due to expression of different HCN channel isoforms. However, as $I_{\mathrm{h}}$ did not differ kinetically between normal and deaf mice, the amplitude difference seems more likely to be related to different $\mathrm{HCN}$ channel density rather than a difference in HCN subunits (e.g. HCN1 channels display more rapid kinetics and are activated at more hyperpolarized potentials than HCN2 channels; see also Brewster et al., 2002). Our previous study (Leao et al., 2004) showed that MNTB neurons in deaf mice are more excitable than MNTB neurons from normal mice, partly due to a decreased contribution of low-threshold $\mathrm{K}^{+}$currents. This increase in excitability could result in an increased expression of $\mathrm{HCN}$ channels in deaf mice, as a result of increased firing activity (Brewster et al., 2002; Bender et al., 2003; Takigawa \& Alzheimer, 2003; Zhang et al., 2003). In our previous study, we also found that, in contrast to potassium currents, calcium currents are the same in MNTB neurons from normal and deaf mice (Leao et al., 2004). Interestingly, in dorsal root ganglion (DRG) neurons, some studies have shown that axotomy causes down-regulation of lowthreshold $\mathrm{K}^{+}$currents, and a recent study by Yao et al. (2003) has shown up-regulation of $I_{\mathrm{h}}$ in axotomised DRG neurons (Park et al., 2003; Yang et al., 2004). Taking these observations into account, our results suggest that the expression of select channels, in particular voltage-gated and hyperpolarization-activated potassium channels, is regulated by the amount of neural activity during development (see Friauf \& Lohmann, 1999). 


\section{Acknowledgements}

We are very grateful to Karen Steel for providing the $d n / d n$ mice for our breeding colony and to Brian Robertson for helpful comments on the manuscript.

\section{Abbreviations}

AP, action potential; AVCN, anteroventral cochlear nucleus; DTX, dendrotoxin; HCN, hyperpolarization-activated cyclic nucleotide gated; $I_{\mathrm{h}}$, hyperpolarization-activated current; $I_{\mathrm{LT}}$, dendrotoxin-sensitive low-threshold voltagedependent $\mathrm{K}^{+}$current; MNTB, medial nucleus of the trapezoid body; PSP, postsynaptic potential.

\section{References}

Bal, R. \& Oertel, D. (2000) Hyperpolarization-activated, mixed-cation current $\left(\mathrm{I}_{\mathrm{h}}\right)$ in octopus cells of the mammalian cochlear nucleus. J. Neurophysiol., 84, 806-817.

Banks, M.I., Pearce, R.A. \& Smith, P.H. (1993) Hyperpolarization-activated cation current $\left(\mathrm{I}_{\mathrm{h}}\right)$ in neurons of the medial nucleus of the trapezoid body: voltage-clamp analysis and enhancement by norepinephrine and cAMP suggest a modulatory mechanism in the auditory brain stem. $J$. Neurophysiol., 70, 1420-1432.

Bender, R.A., Soleymani, S.V., Brewster, A.L., Nguyen, S.T., Beck, H., Mathern, G.W. \& Baram, T.H. (2003) Enhanced expression of a specific hyperpolarization-activated cyclic nucleotide-gated cation channel (HCN) in surviving dentate gyrus granule cells of human and experimental epileptic hippocampus. J. Neurosci., 23, 6826-6836.

Bock, G.R., Frank, M.P. \& Steel, K.P. (1982) Preservation of central auditory function in the deafness mouse. Brain Res., 239, 608-612.

Brew, H.M. \& Forsythe, I.D. (1995) Two voltage-dependent $\mathrm{K}^{+}$conductances with complementary functions in postsynaptic integration at a central auditory synapse. J. Neurosci., 15, 8011-8022.

Brewster, A., Bender, R.A., Chen, Y., Dube, C., Eghbal-Ahmadi, M. \& Baram, T.Z. (2002) Developmental febrile seizures modulate hippocampal gene expression of hyperpolarization-activated channels in an isoform- and cellspecific manner. J. Neurosci., 22, 4591-4599.

Casseday, J.H., Ehrlich, D. \& Covey, E. (1994) Neural tuning for sound duration: role of inhibitory mechanisms in the inferior colliculus. Science, 264, 847-850.

Cuttle, M.F., Rusznak, Z., Wong, A.Y., Owens, S. \& Forsythe, I.D. (2001) Modulation of a presynaptic hyperpolarization-activated cationic current (I (h)) at an excitatory synaptic terminal in the rat auditory brainstem. J. Physiol. (Lond.), 534, 733-744.

Dodson, P.D., Barker, M.C. \& Forsythe, I.D. (2002) Two heteromeric Kv1 potassium channels differentially regulate action potential firing. J. Neurosci., 22, 6953-6961.

Dorval, A.D., Christini, D.J. \& White, J.A. (2001) Real-time linux dynamic clamp: a fast and flexible way to construct virtual ion channels in living cells. Ann. Biomed. Eng., 29, 897-907.
Friauf, E. \& Lohmann, C. (1999) Development of auditory brainstem circuitry. Activity-dependent and activity-independent processes. Cell Tissue Res., 297, 187-195.

Kandler, K. \& Friauf, E. (1995) Development of electrical membrane properties and discharge characteristics of superior olivary complex neurons in fetal and postnatal rats. Eur. J. Neurosci., 7, 1773-1790.

Keats, B.J. \& Berlin, C.I. (1999) Genomics and hearing impairment. Genome Res., 9, 7-16.

Koch, U. \& Grothe, B. (2003) Hyperpolarization-activated current (Ih) in the inferior colliculus: distribution and contribution to temporal processing. J. Neurophysiol., 90, 3679-3687.

Kurima, K., Peters, L.M., Yang, Y., Riazuddin, S., Ahmed, Z.M., Naz, S., Arnaud, D., Drury, S., Mo, J., Makishima, T., Ghosh, M., Menon, P.S., Deshmukh, D., Oddoux, C., Ostrer, H., Khan, S., Deininger, P.L., Hampton, L.L., Sullivan, S.L., Battey, J.F. Jr, Keats, B.J., Wilcox, E.R., Friedman, T.B. \& Griffith, A.J. (2002) Dominant and recessive deafness caused by mutations of a novel gene, TMC1, required for cochlear hair-cell function. Nat. Genet., 30, 277-284.

Leao, R.N., Berntson, A., Forsythe, I.D. \& Walmsley, B. (2004) Reduced lowvoltage activated $\mathrm{K}^{+}$conductances and enhanced central excitability in a congenitally deaf (dn/dn) mouse. J. Physiol. (Lond.), 559, 25-33.

Oleskevich, S., Youssoufian, M. \& Walmsley, B. (2004) Presynaptic plasticity in two giant auditory synapses in normal and deaf mice. J. Physiol. (Lond.), 560, 709-719.

Park, S.Y., Choi, J.Y., Kim, R.U., Lee, Y.S., Cho, H.J. \& Kim, D.S. (2003) Downregulation of voltage-gated potassium channel alpha gene expression by axotomy and neurotrophins in rat dorsal root ganglia. Mol. Cells, 16, 256-259.

Santoro, B. \& Baram, T.Z. (2003) The multiple personalities of h-channels. TINS, 26, 550-554.

Shaikh, A.G. \& Finlayson, P.G. (2003) Hyperpolarization-activated conductances affect brainstem auditory neuron excitability. Hear. Res., 183, 126136.

Strauss, U., Kole, M.H., Brauer, A.U., Pahnke, J., Bajorat, R., Rolfs, A., Nitsch, R. \& Deisz, R.A. (2004) An impaired neocortical Ih is associated with enhanced excitability and absence epilepsy. Eur. J. Neurosci., 19, 30483058.

Takigawa, T. \& Alzheimer, C. (2003) Interplay between activation of GIRK current and deactivation of Ih modifies temporal integration of excitatory input in CA1 pyramidal cells. J. Neurophysiol., 89, 2238-2244.

Yang, E.K., Takimoto, T., Hayashi, Y., de Groat, W.C. \& Yoshimura, N. (2004) Altered expression of potassium channel subunit mRNA and alphadendrotoxin sensitivity of potassium currents in rat dorsal root ganglion neurons after axotomy. Neuroscience, 123, 867-874.

Yao, H., Donnelly, D.F., Ma, C. \& LaMotte, R.H. (2003) Upregulation of the hyperpolarization-activated cation current after chronic compression of the dorsal root ganglion. J. Neurosci., 23, 2069-2074.

Zhang, Y., Oliva, R., Gisselmann, G., Hatt, H., Guckenheimer, J. \& HarrisWarrick, R.M. (2003) Overexpression of a hyperpolarization-activated cation current (Ih) channel gene modifies the firing activity of identified motor neurons in a small neural network. J. Neurosci., 23, 9059-9067. 